\title{
The Role of Pore Structure on Char Reactivity
}

\author{
DOE Grant No.: DE-FG 22-91PC91294 DOE/PC/91294--T1 \\ Quarterly Progress Report \\ DE93 009674
}

\author{
P.I.: Adel F. Sarofim
}

Massachusetts Institute of Technology

Department of Chemical Engineering

Cambridge, MA 02139-4307

\author{
Prepared for U.S. Department of Energy \\ Morgantown Energy Technology Center \\ P.O. Box 880 \\ Morgantown, WV 26507-0880
}

Attention: Wu K. Lan

Period Covered: Up to $4 / 30 / 92$

\section{DISCLAIMER}

This report was preparea as an account of work sponsored by an agency of the United States This report was prepared as an ane their Government. Neither the United States Government nor any agency legal liability or responsiemployees, makes any warranty, express or implied, or assumes any legal liation, apparatus, product, or bility for the accuracy, completeness, or usefulness of any information, apparatus, product, or process disclosed, or represents that its use would not infringe privately owned trade name, trademark, ence herein to any specific commercial product, process, or service by its endorsement, recommanufacturer, or otherwise does not necessarily constitute or imply its endorsentere the views mendation, or favoring by the United States Government or any agency theref. The of the and opinions of authors expressed herein do not

United States Government or any agency thereof. 


\title{
MORPHOLOGICAL CHANGES DURING OXIDATION OF \\ A SINGLE CHAR PARTICLE
}

Matteo d'Amore ${ }^{-}$, Leonardo Tognotti ${ }^{\prime}$, and Adel F. Sarofim ${ }^{0}$

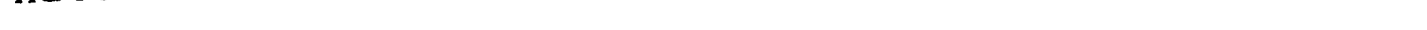

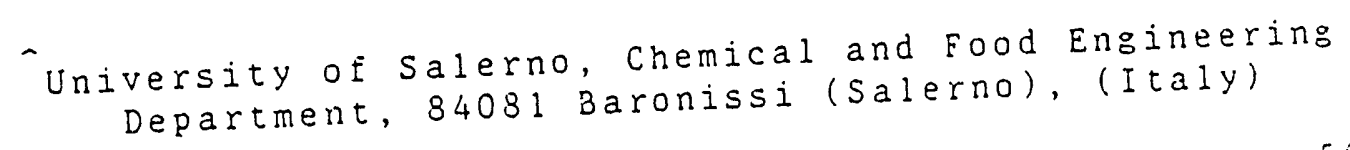




\section{INTRODUCTION}

The reaction rate of carbon burning under chemical kinetic or internal diffusion controlled regime is strongly affected by the pore structure, which governs the extent of penetration of the reacting gases and, through the porosity evolution with conversion, the total amount of surface available for reaction (Gavalas, 1980; Mohanty et al., 1982; Reyes and Jensen, 1986).

The problem of evaluating the variation of comoustion rates with conversion is usually reduced to the purely topological problem of establishing the relationship between accessible surface area and porosity as this latter changes. In the above referenced theoretical studies the assumption is made either that the reactivity is constant over the entire surface or restricted to the non micruporous area (Gavalas, 1980). Accessibility to the microporuus area may be restricted due to hindered diffusion in pures having dimensions approaching that of the reacting molecules and reactivities may vary due to either graphitization of surfaces or non-uniform distribution of catalysts. For this reason it is desirable to experimentally deternine the evolution of pore structure with increasing carbon conversion.

Whatever the experimental technique used, the possible occurrence of phenomena like shrinkage (Hurt et al., 19u3) or fragmentation by percolation (Bar-2ir et a1., 1959; Kerstein and viksa, 1955), complicates the analysis of data to obtain basic information on porosity and suriace area. Moreover, the experimental apparatuses currently used for reactivity measurements and the porosimetry techniques presently available, even when used on small amounts of samples, yield average information, since they integrate the results over the entire number of particles used. Al these uncertainties result in tremendous data scattering (up to four orders of magnitude at a given temperaturel when 
general correlations for intrinsic reactivity of coal chars are proposed (Smith, 1982).

In this study, the changes with conversion in morphology of a carbon char in the temperature range 500-1200 $\mathrm{K}$ are followed by using an electrodynamic balance (EDB) (Spjut et al., 1985; Dudek, 1988; Bar-ziv et al., 1989). This device allows one to measure in situ, over temperature range wider than in other apparatuses, mass, diameter, density, surface area, rate of reaction and temperature for a single, suspended submilimeter particle. By following with the EDB the changes in the char as it reacts, it is possible to study the influence of the porous texture on the reaction behavior and shed some light on the contribution by micropores to the reaction in the chemical kinetic controlled regime.

The pore sizes will be broken down into three classes: micropores (diameters between 0.3 and $3 \mathrm{~nm}$ ), mesopores $(3<d<20 \mathrm{~nm})$, and macropores $(20 \mathrm{~nm}<\mathrm{d})$. The micropores will be determined by $\mathrm{CO}_{2}$ gas adsorption and a significant part of the results and discussions in this paper will be devoted to the interpretation of adsorption data to obtain the finer pore structure. The macropores are traditionally obtained by mercury intrusion porosimetry, alinough precautions must be taken to separate the contribution of interparticle voids from those of the larger macropores (Bellezza, 1935). In this study the result of turi et al. (1988) that the macropore volume is constant during reaction in the kinetic controlled regime will be utilized. This result was based on the observation that all macioleatures of a particle were conserved during reaction in a chemical controlled regime and that the changes in diameters of macropores, down to the limit of resolution of $100 \mathrm{~nm}$ on the electromicrographs, were proportional to the change in the particle diameter. The mesopores are traditionally measured by capillary condeasation with the results being somewhat dependent on the method of interpretation of the 
adsorption-desorption isotherms. In this study the mesopores will be determined from a volume balance utilizing the special capability of the EDB for measuring the density of a single particle.

\section{EXPERIMENTAL}

\subsection{Apparatuses}

\section{Electrodynamic Thermogravimetric Apoaratus}

The electrodynamic chamber consists of three eiectrodes in an hyperboloidal configuration, the theory of wich is described by werker et al. (1959), Davis and Ray (1980), Philip (1981) and spjut (1985). A schematic vieti of the electrodynamic balance is shown in fig. 1. The chamber creates a dynamic electric field capable of suspending a single, charged particle with a characteristic size less than $250 \mathrm{\mu m}$ in the present configuraiton. The $A C$ O: ring electrode provides lateral stability to the particle through an imposed AC field oscillating sinusoldaliy $\$ 2000$ volis at $100 \mathrm{~Hz}$. The DC top and bottom electrodes provide rerical stabilicy by balancing the gravitational force, thus stab: suspending the charged particle in the chamber. A position control system can be used which automatically adjusis the electric field to keep the paricle at the chamber center. An optical microscope is used for vieting the partisiz and for manual control of the particle position. The ristoscope allows the messurement of the particle diameter to $=5$ H. . A $20 \mathrm{~W} \mathrm{CO}_{2}$ laser is used to heat the suspended particie and a two color infrared $(2$ and $4 \mu \mathrm{m})$ pyrometry is used for temperature measurements. A gas flow system allows one to react a paricle in various gaseous enviroments. Aititional details on the experimental apparatus and procedure cail be found in spjut et al. (1985), Bar-ziv et al.(1989), Dudek et a 1. (1988). 


\section{Porosimetry}

The pore size distribution of the char was measured by means of a Carlo Erba sorptomatic 1800 static-volumetric apparatus, using $\mathrm{N}_{2}$ at $77 \mathrm{~K}$ or $\mathrm{CO}_{2}$ at 195 and $298 \mathrm{~K}$ as adsorption gases, and a high pressure mercury porosimeter model Carlo Erba 2000. The EDB was used as a gravimetric apparatus for $\mathrm{CO}_{2}$ adsorption measurements on single "Spherocarb" particles at $298 \mathrm{~K}$.

\subsection{Char properties}

The model char used in this work was "spherocarb", a spherical microporous carbon from Analabs Inc.. The 60/30 mesh commercial fraction has been used in several previous studies (waters et al., 1983, Dudek et al., 1938, D'tmore et a. 1., 1983, Hurt et a1., !953) because of its high degree ot uniformity and sphericity. Furthermore, the low asi content of the particles minimizes the effects of caialytic impurities, while the lisited amount of volatile matrer precludes the complicating efiects oi devolatilization on the burning behaviour. The gross pinysical properties and the chemical analysis of the material are repories in the following section.

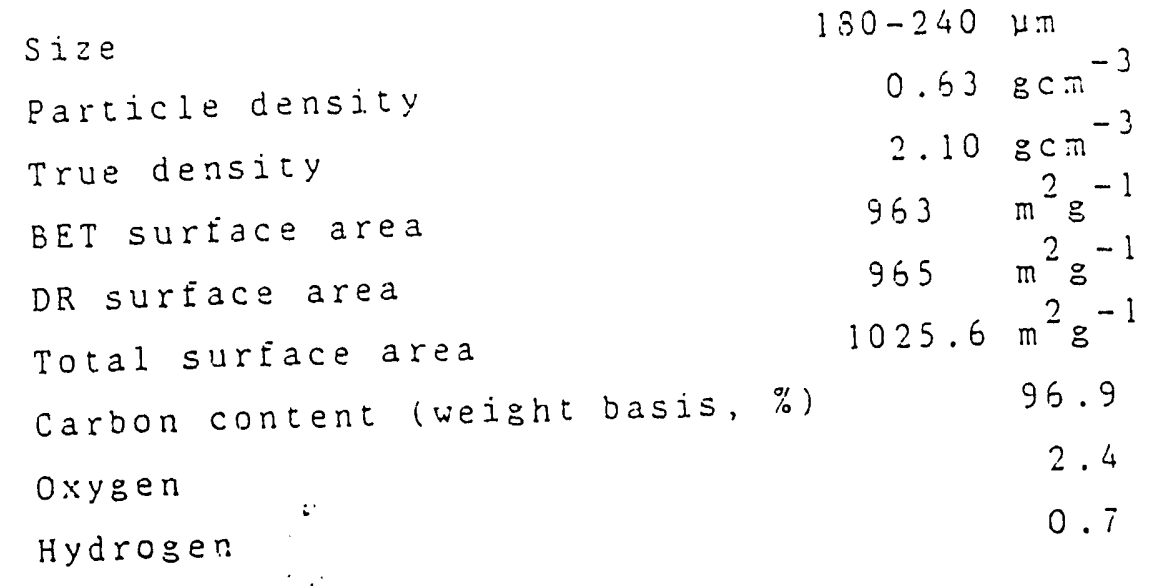


The BET area was obtained by analysing the $\mathrm{N}_{2}$ adsorption isotherm at $77 \mathrm{~K}$. Analysis of the $\mathrm{CO}_{2}$ adsorption data at 195 and at $293 \mathrm{~K}$ by the Dubinin-Raduskevitch equation save the $D R$ area. The total surface area includes those of the micro-, meso-, and macro-pores. The good agreement between the BET and the DR suriace areas obtained in this case is somehow unexpected. Capillary condensation of the adsorption gases in the microporosity should be misinterpreted by Bet theory, which in this case would overestimate the sample suriace area. On the other hand, indications have been given in the past that $N_{2}$ at $i i k$ hardly reaches tine whole microporosity oi chars. These counterbalancing eifects could lead to the agreement above outlined.

Figure 2 shows the cumulative pore size distribution of the "Spinerocari" on a volume basis. The distribution has been obtained by joining distribution curves from gas adsorption together with results oi high pressure mercury: porosimetry (Dubinin, 196i; spitzer et al., libi. Tile method or Medet (197i) has been used to deteraine the size distribution of the micropores. Size disiribution of mesopores has been obtained from adsorption data according to the method. of Dollimore and Heal (1970). Mercury porosimetry has been used to determine the size distribution of macropores.

\subsection{Experimental procedure with EDB}

Atter capture in the EDB each particle was wighed by the technique described in detail elsewhere (D'Anore tet al.. 1933), and its diameter, density, porosity (D'Amore et ab. 1988), surface area (Dudek et al. 1938) measured. The concentration of the gases flowing through the EDB was selected to include 5,21 or $100 \% \mathrm{O}_{2}$ in $\mathrm{N}_{2}$ or chromatographic-grade $\mathrm{CO}_{2}$. The particle was heated by the $\mathrm{CO}_{2}$ laser to the desired temperature which was measured by 
$\therefore+\cdots: \because ;$

the two color optical pyrometry and continuously recorded. A semicontinuous reaction technique was utilized arresting the reaction by turning the laser off, and measuring at various conversions the physical parameters of the particle.

\section{RESULTS}

\subsection{Microdorosity}

\section{Theory}

The adsorption data have been interpreted using the BET equation in the linear form:

$$
\frac{p / p_{s}}{s\left(1-p / p_{s}\right)}=\frac{1}{s_{m} c}+\frac{c-1}{s_{m} c}\left(p / p_{s}\right)
$$

where $s$ and $s_{m}$ are the number of moles of gas adsorbed at relative pressure $p / p_{s}$ and in a complete monolayer, per unit oi sample mass, respectively.

For chars with a high fraction of microporosity, the low- and medium-pressure parts of isotherms are analysed using the Dubinin and Astakhov equation (Dubinin and Astakinov, 19i1):

$$
\theta=\frac{\omega}{\omega t s}=\exp [-(A / E)]^{h}
$$

where w/w ${ }_{t s}$ is the ratio of the micropore volume willed at pressure p/ps to the total micropore volume wis, i.e. the degree of filling of micropores $\theta$; $E$ is the characteristic free energy of adsorption; $A$ is the differential molar work of adsorption and is given by:

$$
\therefore=R T \ln \left(p_{S} / p\right)
$$




$$
\ln s-\ln s_{t s}=-(R T / E)^{h}\left[\ln \left(p_{s} / p\right)\right]^{h}
$$

For $h=2$ eq. (4) reduces to Dubinin-Raduskevitch equation $(D R)$.

According to Medek's analysis (1977) the equation for the differential micropore size distribution is given by:

$\frac{d \theta}{d r_{e}}=\frac{d \omega}{{ }_{t s} d r_{e}}=3 h(k / E)^{h} r_{e}^{-(3 h+1)} \exp \left[-(k / E)^{h} r_{e}^{-3 h}\right]$

where $\theta$ is the degree of filling of micropores, $r$ the pore radius, $k$, evaluated according to Dubinin's aijinity postulate, is equal to $7.5110^{-25} \mathrm{cal} \mathrm{m}^{-3}$ mole $\mathrm{e}^{-1}$.

\section{Evolution of "Spherocarb" morphology with reaciion}

By taking advantage of the special ieatures of the electrodynamic balance, changes in physical characterisizcs of single "Sperocarb" particles with reaction hare been followed.

The volume of micropores wis of single "spierocarb" particies have been evaluated from the CO 2 adsorgtion isotherms at $298 \mathrm{~K}$ obtained in an E.DB by the use oi the DR equation. A complete description of the technique is siven by Dudek et al. (1988). These volumes can be related to the surface areas of the micropores (Lamond and Marsh, 1964; Gan et a1., 1972; Rand, 1974; Marsh et al., 1975). The char pores volumes are here reported (Fisure 3 ) per unit nias of the particle being measured. In Figure 3, wis is reported versus fractional conversion $f$ defined as the weight loss divided by"the initial mass of carbon, for eight separate 
single particle "Spherocarb" oxidations. Five of the runs have been performed in oxygen, two in $\mathrm{CO}_{2}$ and one in air. The reaction temperatures are in the range 750-830 $\mathrm{K}$ for reactions in oxygen and $1200-1250 \mathrm{~K}$ for reactions in $\mathrm{CO}_{2}$. The initial specific volume of the micropores vary from 0.203 to $0.276 \mathrm{~cm}^{3} \mathrm{~g}^{-1}$ with the average being $0.237 \mathrm{~cm}^{3} \mathrm{~g}^{-1}$. These specific volumes can be compared to a value of 0.237 $\mathrm{cm}^{3} \mathrm{~g}^{-1}$ obtained on a $0.294 \mathrm{~g}$ sample of "spherocarb" (about 100,000 particles!) by Hurt et al (1933) in a conventional gravimetric apparatus. The specific volumes of the micropores for the $0.294 \mathrm{~g}$ sample at conversions of $f=0$ and $\mathrm{E}=0.65$ for an oxidation run with air are also in figure 3 .

Adsorption can give, in addition to the total microporosities volumes, the pore size distribution by the use of eq. (5). Normalized distributions for Eractional conversions f of $0.14,0.23$ and 0.52 for a single particle reacting in air at $770 \mathrm{~K}$ are compared in Figure 4 with the distributions for the unreacted char. Although the total microporous volume decreases, the fractional distribution of the residual pores is remarkably constant. This is consistent with the micropore elimination mocel of Hurt et al., (1983), which was presented with an alternative pore shrinkage model to explain the observation of shrinkage of particles when chemical kinetics are controling.

\subsection{Meso-and macro-porosities}

The meso- and macro-porosities are obtained by volume balances on the single particle usins measurements of the weight and volume of the particle to obtain total porosity.

Figure 5 shows the single particle porusity $E$ as a function of conversion for the same separate "spherocarb" oxidations. The porosity values have been obtained from the particle densities by the relation: 


$$
E=\left(1-\rho / \rho_{t}\right)
$$

where 0 is the density of a "Spherocarb" particle at a given conversion and $o_{t}$ is the "spherocarb" true density. Density measurements were performed discretely using the aerodynamic drag force technique (D'Amore et al., 1988). Initial porosities ranged from 0.56 to 0.68 . Although conventional theory would predict particle porosity to increase linearly with conversion under kinetically controlled conditions (zone I) up to $E=1$, the figure shows that the linearity holds up to a conversion of only 40-50\%. A sort of plateau is then approached, consistent with the shrinkage-densification model proposed by Hurt et al. (1988) for chars undergoing regime $I$ or kinetically controlled oxidation.

A particle shrinkage factor $\sum$ has been defined as the ratio of the particle volume $v$ to the initial voluse $V_{0}$. The $\sum$ values for the eight runs above have been reporied in Fig. 6 as a function of conversion. The straight solid line in the figure represents a conventional shrinking, constant density, particle model, while the line at $\Sigma=1$ is representative of a purely internal reacion inthout shrinkage. The data indicates that the exient of "Spherocarb" shrinkage is not a function of tempe:ature, or reacting gas, but only a function of conversion.

The data on total porosity and micropnrosity obtained in the EDB for a single particle allow one to evaluate the meso- and macropore volume of the particle at a given conversion. This can be done by a volume balance, given by the relation:

$$
w=\left(1 / p-1 / p_{t}-w_{t s}\right)(1-f)
$$


where $W$ is the volume of the meso-plus macro-pores per unit initial mass. The results of such an analysis are reported in Fig. 7. In the figure, w has betn normalized for each run with the initial value $W_{0}$, to account for the different charucteristics of the single particles tested. In spite of the large differences in the initial porosity of the single particles (D'Amore et al., 1988), and in the experimental conditions, clustering of the data points about one curve indicate that the particles all exhibit the same behavior: meso-plus macro-porosity increases with reaction, reaches a maximum at about $\mathfrak{f}=0.3$ and eventually decreases to zero at $\mathrm{f}=1$, when the solid is consumed.

The meso- plus macro-pore volume fractions can be separated by utilization of the results of Hurt et al. (1938). Based on electronmicrographs studies of particles reacted to different fractional conversions, visible macropores (diameters greather than $100 \mathrm{~nm}$ ) were iound to have a constant volume fraction as particles shrank during conversion. Utilizing this information we are now in a position to show how the micro-, meso-, and macro-pore volumes change with conversion (Big. $b$ ), with the microporous volume iraction decreasing, the miesoporous volume fraction increasing, and the macroporous itaction remaining constant. These variations have implications on how the internal surfaces participate in the chemical reaction, which will be a subject of a subsequent paper.

4. CONCLUDING COMMENTS

pore size distributions have been obtained for single particle using gas adsorption for micropores, the observed constancy of the macropores and a volume balance for the mesopores. The ability of the electrodynamic balance to measure densities of single macroporous particles, without need to differentiate as in conventional liquid displacement methods betweer macropores and interparticle interstices, 
provides a ready way for obtaining the mesoporous regime. The results can be depicted graphically as pie charts as shown for three conversions in Fig. 9.

The study provides support for the hypothesis of Hurt et al. (1988) that densification of the microporous regions is due to pore elimination. The interesting finding is the increase in the mesoporous region with increasing conversion, suggesting a crucial role for the mesopores in the reaction.

\section{REFERENCES}

Bar-ziv E., Jones D. B., Spjut R. E., Dudek D. R., Sarofim, A. F. and Longwell, J.P. (1989). Measurements of Combustion kinetics of a Single Char Particle in an Electrodynamic Thernogravimetric Analyzer. Comb $s$ Flame, $75,81,1989$

Bellezza, C. (1985). Indagine di porosita' di carboni di varia natura. Naples, Dept. of Chem. Eng. Dissertation.

D'Amore A., Dudek, D.R., Sarofim, A.F., and Longwe 11 J.P. (1983). Apparent particle density of a fine particle. Powder Tech., 56, 129.

Davis E.J. and Ray, A.K., J. (1980). Single aerosol particle size and mass measurements using an electrodynamic balance. J. Colloid Intertace Sci. $75,566$.

Dollimore, D. and Heal, G.L. (1970). Fore Size Distributions in Typical Adsorbent systems. J. Colloid Interíaces Sci. 33,508

Dubinin, M.M. (1966) in Chemistry and Physics of Carbon (edited by p. L. Walker) Vol. 2, p. 86, Marcel Drekker, New York

Dubinin, M.M. and Astakhov, V.A. (1971). Adv. Chem. Ser. 102,69

Dudek, D.R. (1983). Single Particle, High Temperature, Gas-Solid Reactions, Mass. Inst, of Tech. PhD Thesis

Dudek, E.R., Longwel1, J.P. and Sarofim, A.F. (1935) Single Particle Surface Area Measurements in the Electrodynamic Balance. Energy \& Fuels, $3,24$. 
Gan, H., Nandi, S.P. and Walker, P.L., Jr. (1972). Fuel. 51, 272

Gavalas, G.R. (1980). A Random Capillary Model with Application to Char Gasification at Chemically Controlied Rates. AIChE. 26, 577

Hurt, R.H., Dudek, E.R., Sarofim, A.F. and Longwell, J.P. (1988). The Phenomenon of Gasification Induced-Carbon Densification and its Influence on pore structure Evolution. Carbon, 26,433 ,

Kerstein, A.R., and Niksa, S. (1985). Twentieth Symp. (Int.) on Comb. The Combustion Institute, Pittsburgh, Pa. p. 941

Lamond, $T$. and Marsh H. (1964). The Surface Properties of Carbon. I I The Effect of Capillary Condensation at Low Relative Pressures upon the Determination of Surface Area. Carbon. 1, 281

Marsh, H., Iley, M., Berger, J. and Siemieniewska (1975). Carbon, 13, 103

Medek, J. (1977). Possibility of Micropore Analysis of Coal and Coke from the Carbon Dioxide Isotherm. Fuel. 56, 131

Mohanty, K.K., Ottino, J.M. and Davis, H.T. (1982). Reaction and Transport in Disordered Composite Media:

Introduction of Percolation Concepts. Chem. Engng. Sci. 37,905

Philip, M.A. (1981). An Absolute Method for Aerosoi Particle Mass Measurement M.S. Thesis, Massachusetts Institute of Technology, Cambridge, Ma, 1981

Rand, B.J. (1974). J. Colloid Interface Sci. 45, 133

Reyes, S. and Jensen, K.f. (1936). Percolations concepts in Yodelling of Gas Solid Reactions - I. Application to Char Gasification in the Kinetic Regime. Chem. Engng. SCi. 41,333

Smith, I.W. (1982). The Combustion Rates of Coal Chars: A Review. Nineteenth Symp. (Int.) on Comb. The Combustion Institute, Pittsburgh, Pa.p. 1045

Spitzer, $2 \therefore$ Biba, $V$. and Kadlec, $0 .(1976)$. The Complete Pore Structure Analysis of Fine Porous Solids, 14, 151

Spjut, R.E. (1985). Heat Transfer to and Position control of Electrodynamically suspended Micron-sized Particles. Mass. Inst. of Tech. Cambridge, Ma. Ph.D. Thesis 
Spjut, R.E., Sarofim, A.F., and Longwel1, J.P. (1985). Laser Heating and Particle Temperature Measurement in an Electrodynamic Balance. Langmuir, 1, 355 .

waters, B.J., Squires, R.G., and Laurendeau, N.M. (1988b). Morphological Development and Intrinsic Reactivity for Combustion of Two Microporous Carbon Chars. Comb. Sci and Tech. 62,187

Wuerker, R.F., Shelton, H., and Langmuir, R.V. (1959) Electrodynamic Containment of Charged Particles. J. App 1. Phys., 30 , No 3,342 .

LIST OE SYMBOLS

Upper case symbols

A differential molar work of adsorption, cal mol

E characteristics free energy of adsorption, cal mol ${ }^{-1}$

$R$ gas constant, $1.987 \mathrm{cal} \mathrm{mol}^{-1}$

$T$ particle temperature, $K$

$\checkmark$ particle volume, $\mathrm{cm}_{3}$

$v_{0}$ initial particle volume, $\mathrm{cm}_{3}$

w single particle meso-plus macropore volume per unit initial mass, $\mathrm{cm}^{3} \mathrm{~g}^{-1}$

$w_{0}$ single particle initial meso- plus macropore volume per unit mass, $\mathrm{cm}^{3} \mathrm{~g}^{-1}$

Lower case symbols

c parameter in BET equation

f Eractional conversion

$h$ parameter in Dubinin equation

$k$ interaction constant in eq. (4). For $\mathrm{CO}_{2}$ $k=7.5110^{2} \mathrm{cal} \mathrm{nm}^{-3} \mathrm{~mole}^{-1}$.

p adsorption gas pressure, atm

$P_{s}$ adsorption gas saturation pressure, atm

$r$ pore radius, nm 

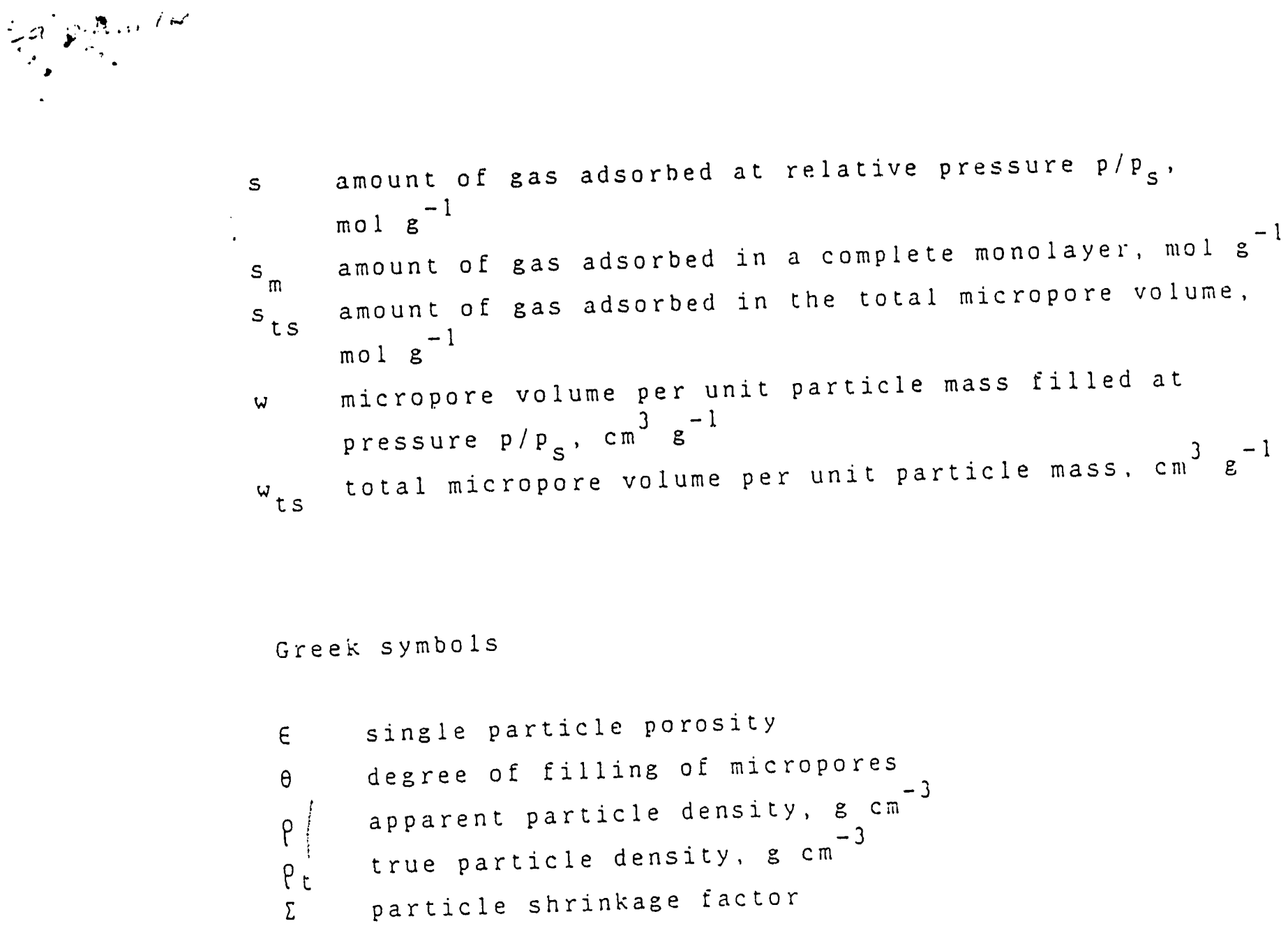
$40 \div 315$

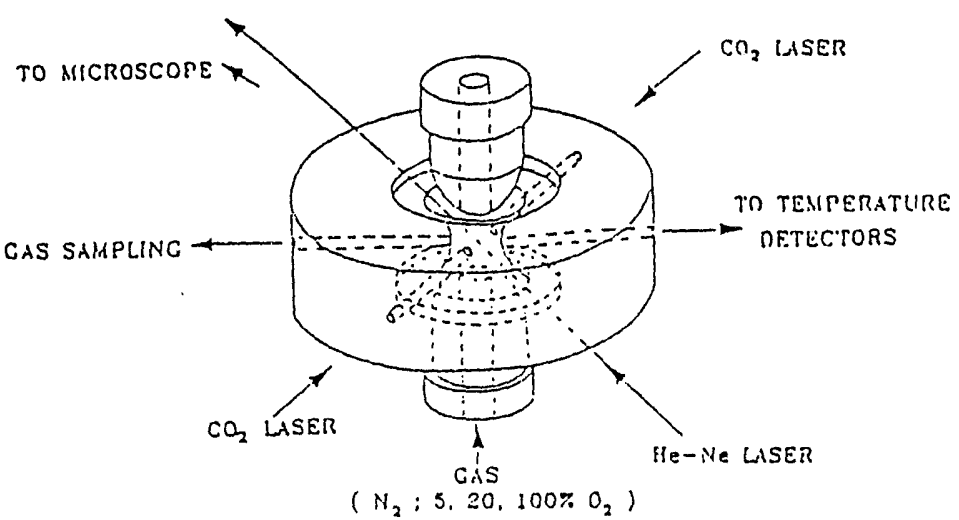

Eig. 1 - The Electrodyanic Thermograciacorb Analyser

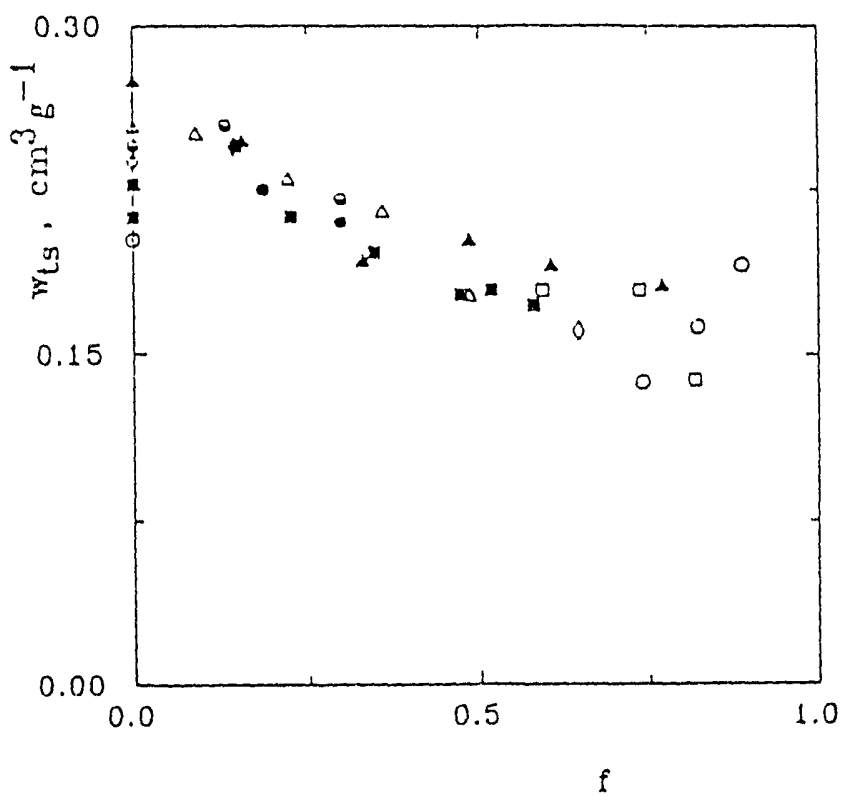

Fis. 3 - Elghc separale single parcicle "Spherocaro" oxidations in 503 .

Macropores volume per unat partacle nas as a iuncizon oi collversion. $0 \wedge \triangle 00100 \% 0$ :

- $10 .: 0 \%$

n 100.000 "5pherocarb" particles oxidation U1 2 i: 0, in

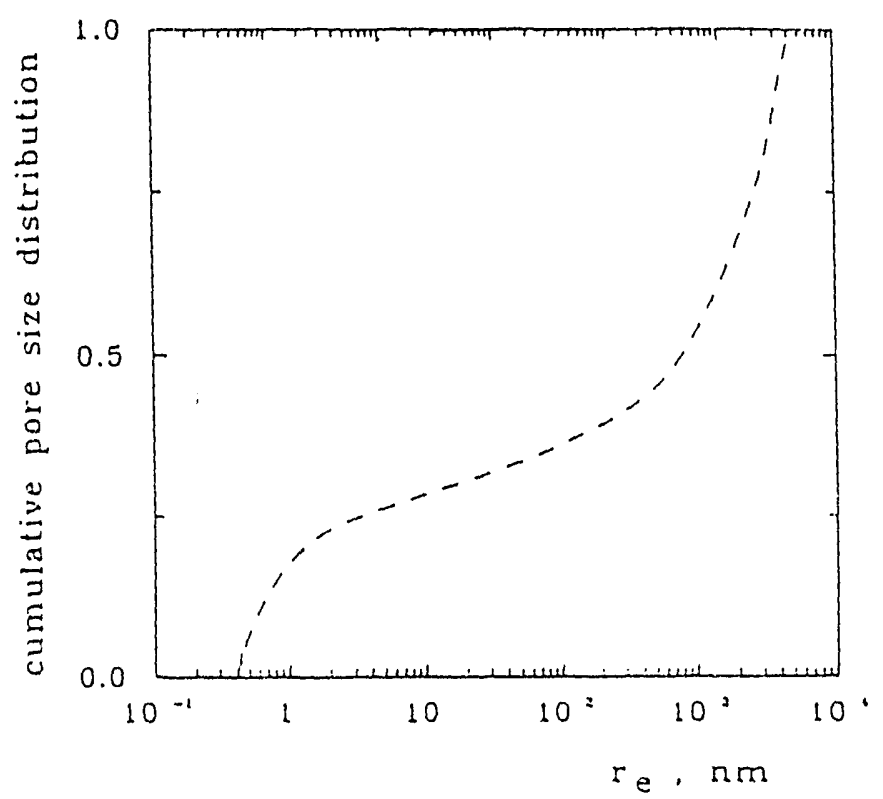

Fab. 2 - Cumulative pore size distrijulion on volume

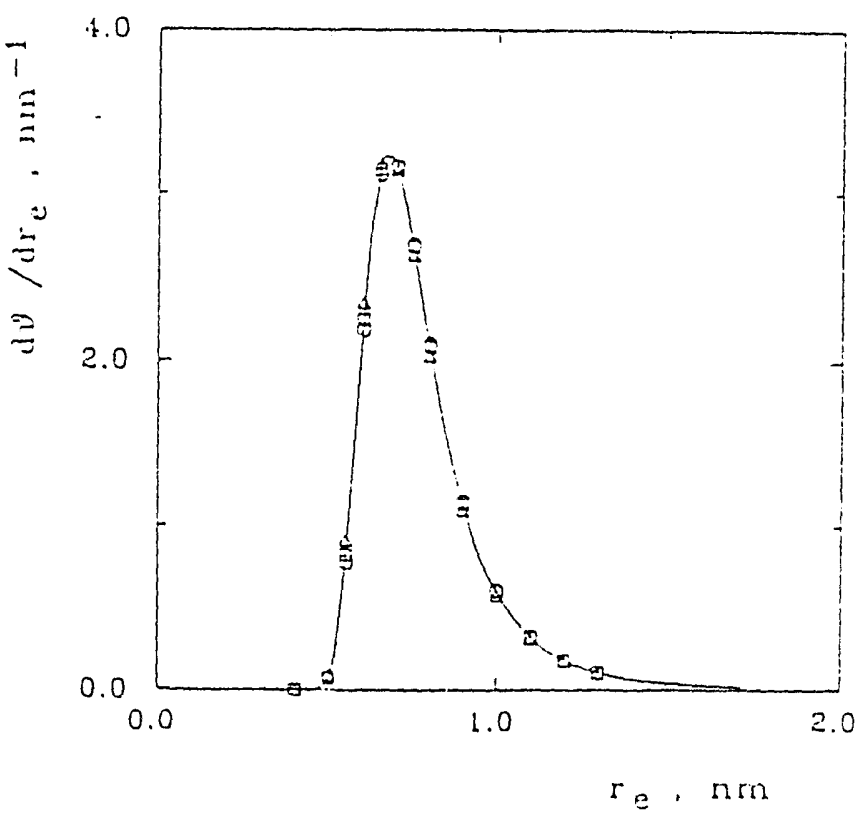

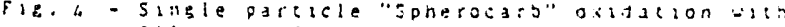
$: 1: 0$, in 203.

yieropolas size ciscrizution at virious conversions.

$\frac{\Delta}{0}(\cdot 0.14$

solad line unreacted car
} 


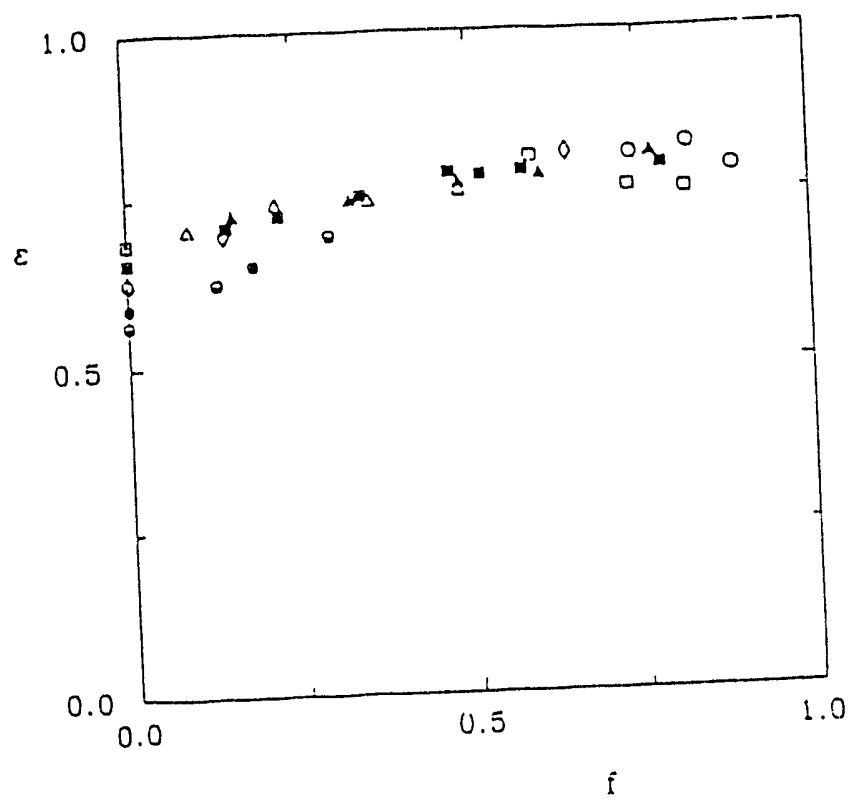

Fat 5 Eagt separace sangle particle "spherocaro" oxications in E:s.

a iuncison oi calletsion. OA $\triangle 20100: 0$ ?

$\begin{aligned}-2: & 0 ; \\ 100: & 0\end{aligned}$

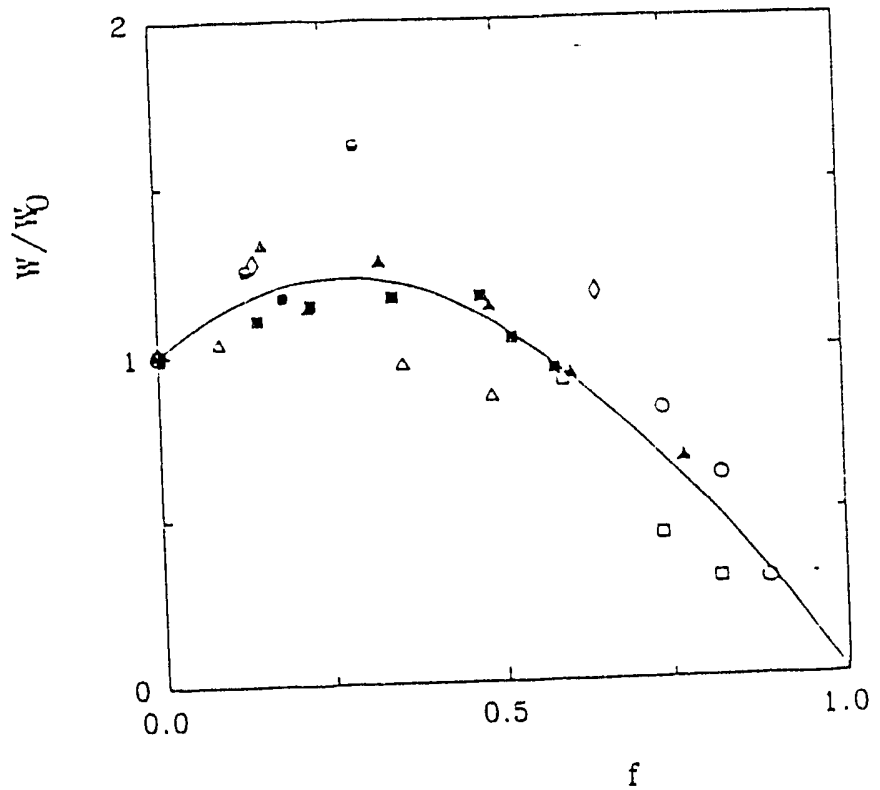

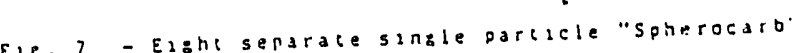

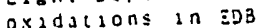

Dxidalions Particle ricso-plus macroporiesolut the inltial mass. normalized lon of calliersion.

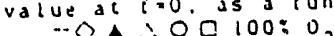

$\begin{array}{lll}0 & 0 & 100: 0 \\ 0 & 21: 0 ?\end{array}$

$100: 0^{2}$

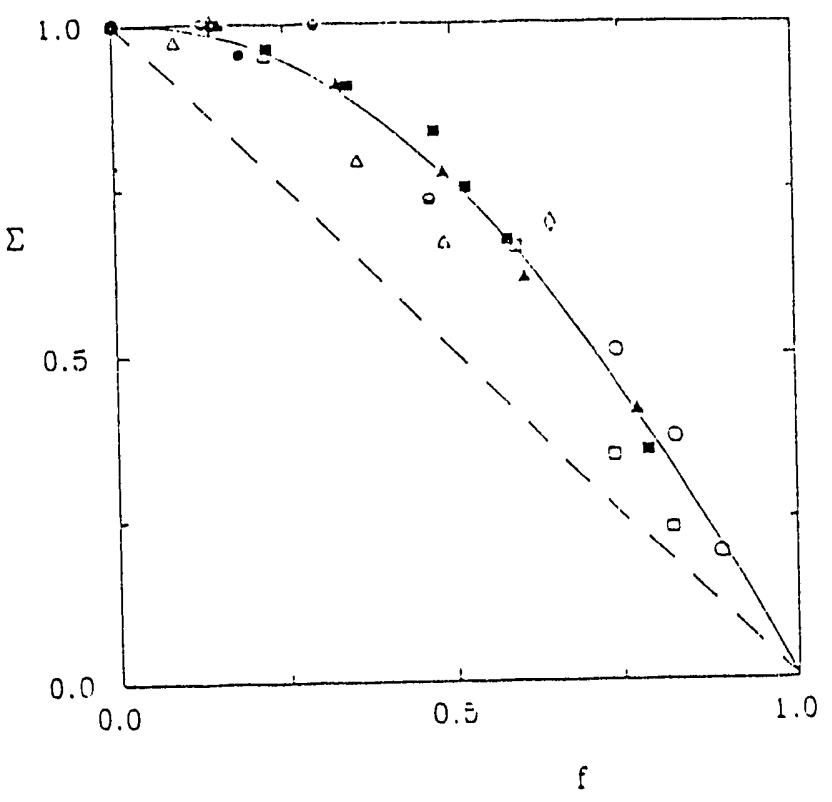

Fig. j- Elght sepurace sinple paricle "jpherocaro"

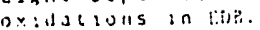

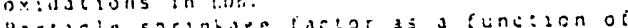
conversion.

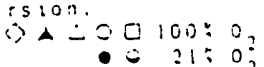

a $100 \div 0$

dashed line sincilling

solid lilie oest ili lase

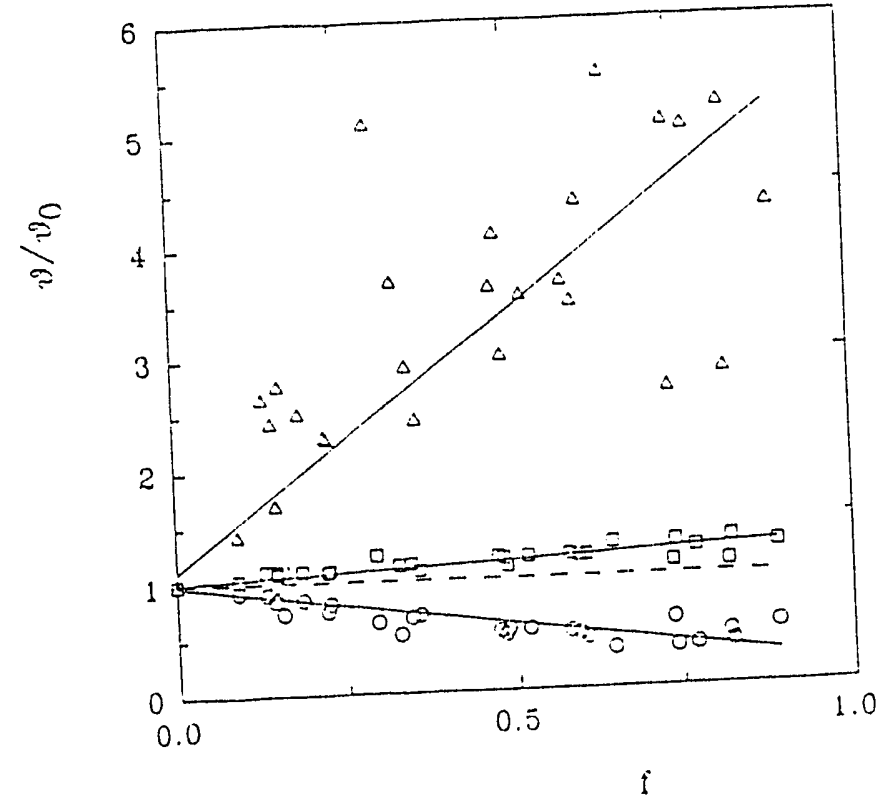

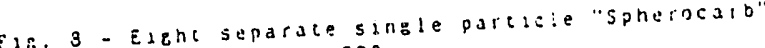
oxidacions 1 in EDB. pures volume tractions. normitisod cuncersloll. the valut at $i=0$, as d tulleston ot converston

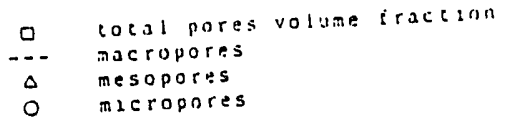

solid line best fat lane 

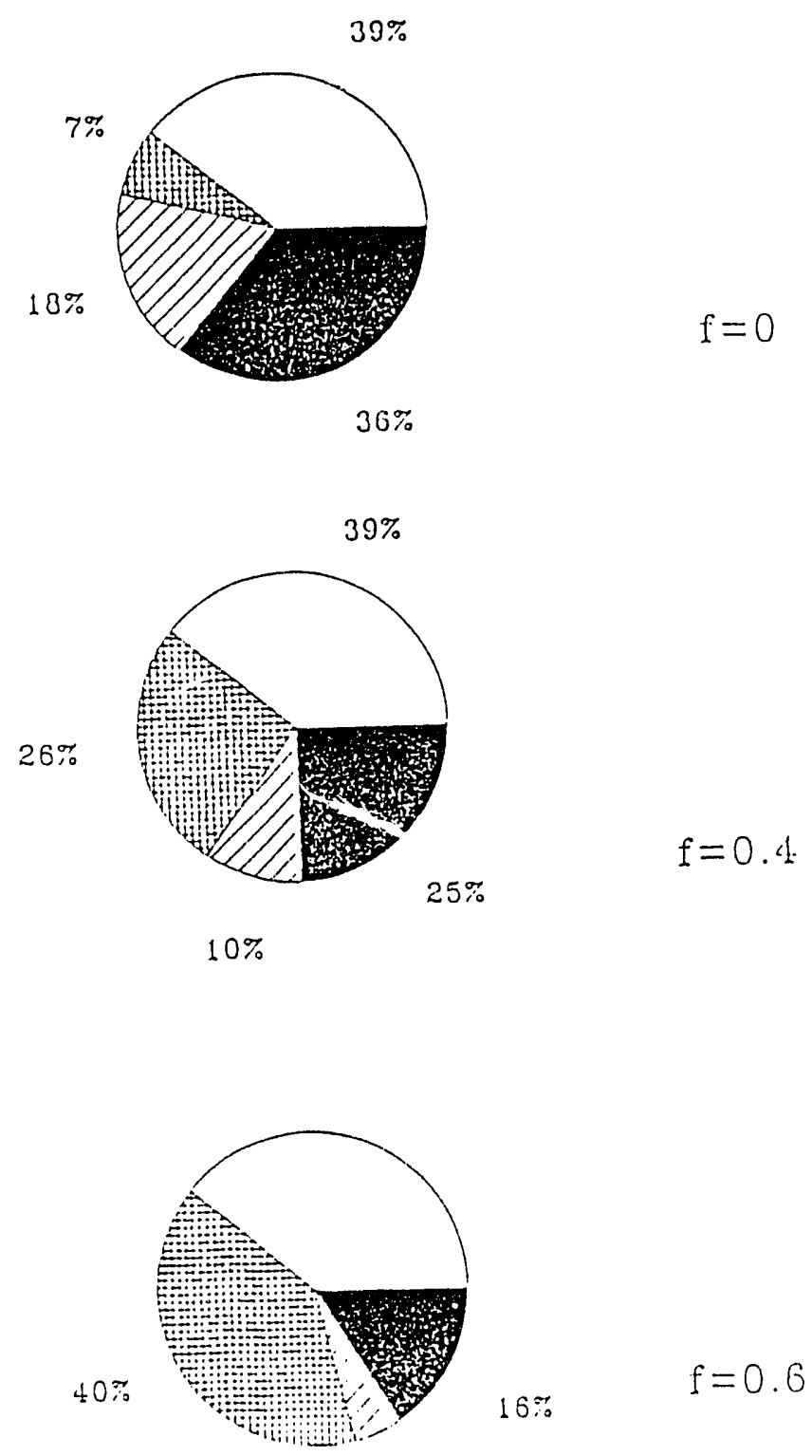

$5 \%$ Fig. 9 - Single particle "Spherocarb" oxidation in EDB.
Volume fraction of pores and carbon at various conversions. 

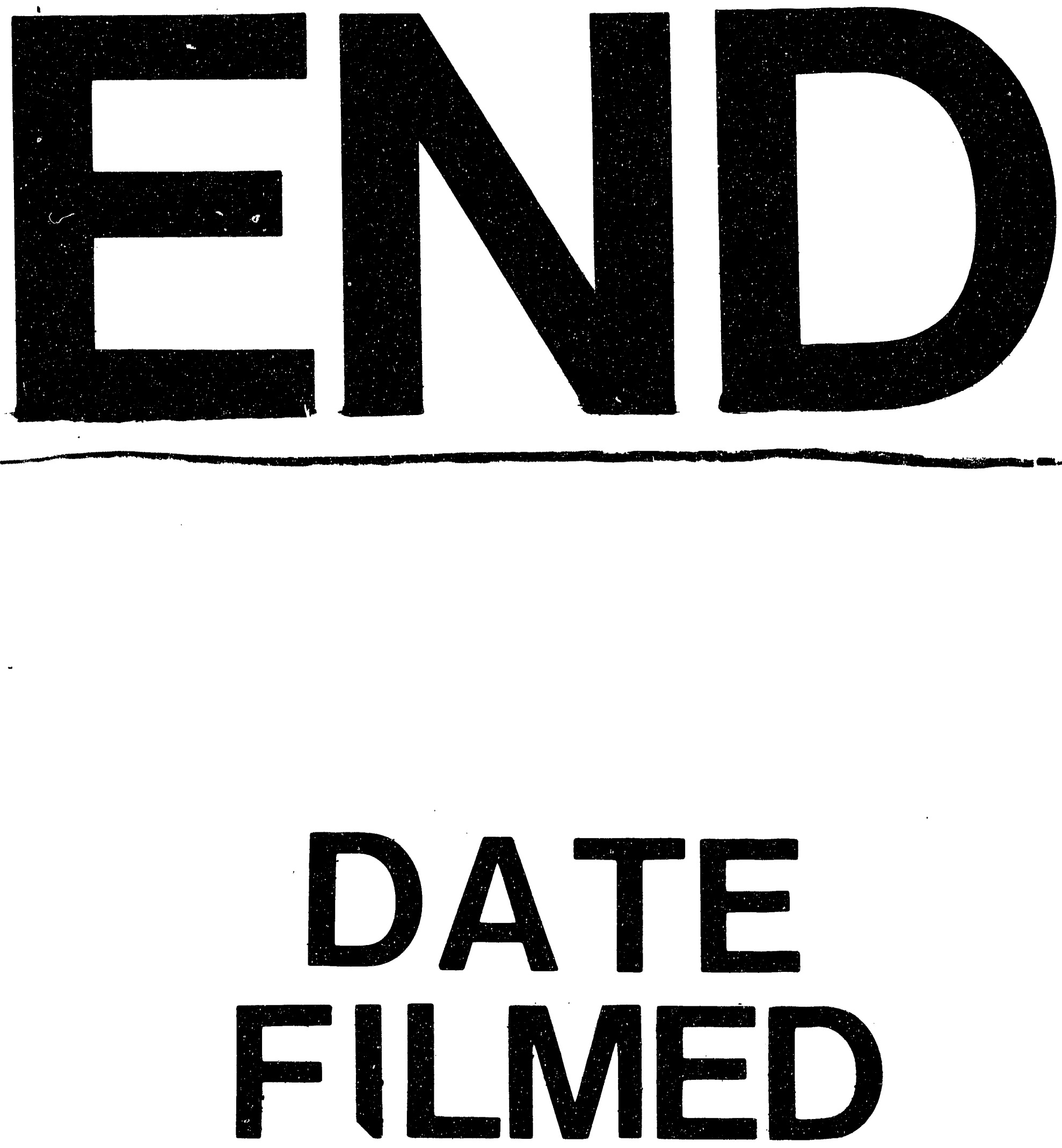

章

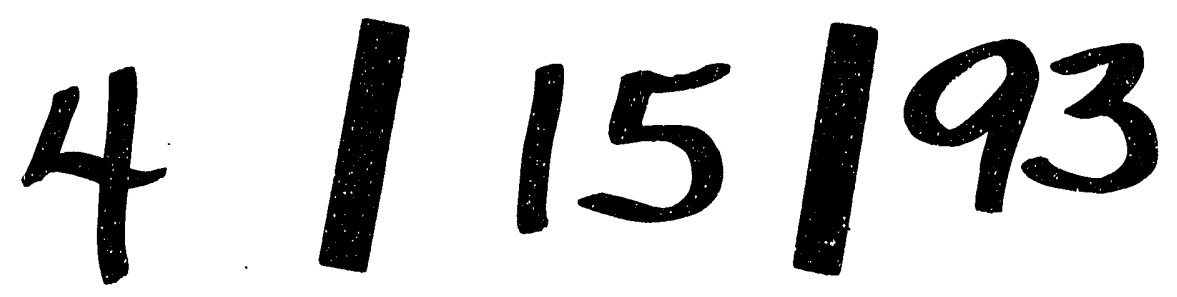


